\title{
LOS PAÍSES DEL ESTE NUEVO FOCO DE EMIGRACIÓN DE LA EUROPA ACTUAL. SU INCIDENCIA EN ESPAÑA
}

POR

\author{
M. ${ }^{a}$ PILAR GONZÁLEZ YANCI Y M. ${ }^{a}$ JOSÉ AGUILERA ARILLA
}

\section{Introducción}

Tras diez años de trabajo dedicados al estudio de los movimientos migratorios en España, vamos a analizar ahora el grupo de los inmigrantes procedentes de la Europa Central y Oriental. Este colectivo, aunque muy heterogéneo, no sólo por los países que engloba (Albania, Bulgaria, CEI, Repúblicas Checa y Eslovaca, Hungría, Polonia, Rumanía y ex Yugoslavia), sino también por ser expresión de un mosaico de etnias y religiones, aparece como una unidad tras establecer el criterio de haber pertenecido a los países con un régimen comunista hasta el año 1989, en el que la caída del muro de Berlín supone un gran cambio en aspectos políticos, económicos y sociales en todo el mundo. La nueva situación europea va a tener una indudable repercusión en la movilidad de estos pueblos, a la que tienen una tendencia ancestral.

El presente trabajo, lejos de pretender un análisis exhaustivo de las características de los migrantes procedentes de estos países, que en gran medida ya se pueden deducir del estudio que dedicamos a la emigración polaca (Aguilera, M. J.; González Yanci, M. P., y Rodríguez, V., 1996), al ser ésta la procedencia más numerosa, quiere mostrar una instantánea de su presencia en España en el contexto del nuevo espacio migratorio europeo. Se trata de analizar su historia migratoria y las circunstancias actuales favorecedoras de la emigración, que no escapan a la celeridad de todos los fenómenos de este final de siglo.

Estudios Geográficos

Tomo LXI, 2000, n. ${ }^{\circ} 239$, abril-junio 


\section{Factores de la nueva situación migratoria}

Si nos centramos en el último cuarto del siglo $\mathrm{xx}$, uno de los cambios acaecidos es la transformación de España en país de inmigración, hecho reforzado por la aparición del retorno. Hasta el año 1975 en nuestro país residían muy pocos extranjeros $(0,6 \%$ del total de la población censada en 1971). Entre ellos predominaban los europeos occidentales, norteamericanos y latinoamericanos, que llegaban por causas económicas, políticas, etc. En 1994, la proporción de extranjeros entre la población española era el 1,6\%. Este aumento en número y proporción lleva consigo una diversificación en las nacionalidades mejor representadas, siendo ahora magrebíes, algunos asiáticos y centroamericanos, los más numerosos. Junto a ellos apuntan otros a los que por tener menor proporción se ha dedicado menos atención, aunque sus particulares circunstancias les hacen merecedores de notable interés. Son, entre otros, los inmigrantes de los países del Centro y Este de Europa.

Varias han sido las circunstancias que han favorecido el cambio de tendencia en nuestro país. Por una parte cambios internos: unos políticos, como el paso de un régimen dictatorial a una democracia constitucional de tipo occidental; económicos, reflejados en la mejora del nivel de vida, la nueva presencia en Europa, el elevado puesto de España en el ranquing mundial de indicadores económicos y sociales, el mayor número de turistas españoles en el extranjero; demográficos, manifestados en el descenso de la natalidad hasta tasas próximas al crecimiento cero y en el envejecimiento de la población. Por otra parte, aspectos derivados del antiguo comportamiento emigratorio generaron hechos como la falta de una legislación concreta respecto a la entrada y permanencia de extranjeros en nuestro país, ya que hasta 1985 no hubo una normativa legal para la acogida y estancia de inmigrantes extranjeros («ley de extranjería»). La existencia de una economía sumergida supone un factor importante de atracción, para empresarios que favorecen la llegada de trabajadores extranjeros cuando los autóctonos son escasos, o demasiado costosos en determinados sectores de actividad (agrario, construcción, servicios y manufactureros) y por empleados extranjeros que aceptan ese trabajo a salarios más bajos que los nacionales, porque su necesidad es mayor y la referencia con los de su país los hace atractivos. Otra razón que influye de forma indirecta es el ser España el tercer destino turístico mundial, constituyendo la vía de 
entrada de gran número de extranjeros que posteriormente se quedan de forma irregular. Por último, la posición geográfica de España se suma, en un momento favorable como el actual, a todas estas causas de atracción de inmigrantes.

Como factores externos se pueden citar algunos de los acontecimientos internacionales que provocaron cambios económicos en el mundo. En 1973-75, la crisis del petróleo ocasionó que países europeos de tradición inmigratoria, se plantearan políticas restrictivas a la entrada de nuevos inmigrantes e incluso de ayuda a los retornos voluntarios. El crecimiento económico de los países euroepos se fue ralentizando en el último decenio llegando a aparecer el paro en muchos de ellos (Consejo de Europa, 1991). Desde los años ochenta y más todavía desde el cambio político del 89, en los países del Este se crea una nueva situación que hace aparecer en Europa un nuevo foco de emigración, justo en el momento en que los del sur mediterráneo, que lo fueron desde los sesenta y antes, cambian su signo. Foco que se suma a los más tradicionales del Norte de África y de tierras más lejanas, todos ellos con importantes y diversos factores de repulsión (mala situación económica, elevado déficit de puestos de trabajo, sobreempleo en sectores básicos, notable juventud de la población con tasas de natalidad importantes...).

A estas circunstancias internas y externas, que son factores de atracción o repulsión para los territorios de salida o de acogida, hay que añadir los de tipo personal de los habitantes que constituyen el potencial migratorio. Éstos van desde las presiones sociales, políticas, religiosas, ambientales, etc., hasta las más subjetivas e incluso, la información que tiene cada sujeto de las posibilidades que ofrecen otros países. Ésta puede provenir de otros emigrantes, de los medios de comunicación, o de sus propios viajes. Todo ello puede, si no ser motivo exclusivo, sí contribuir a la decisión de emigrar. También los gobiernos fomentan, en algunos casos, la salida de emigrantes, ante la seguridad de poder mejorar con ello la economía de sus países. De ahí la existencia de acuerdos bilaterales entre países necesitados de mano de obra y países con excedente de la misma.

Si los países que tradicionalmente recibían emigrantes se encuentran con problemas de nuevas recepciones e incluso de permanencia de los antiguos inmigrantes, los de tradición emigratoria ven reducidos sus lugares de acogida, ante lo que reaccionan diversificando sus destinos. Por ello, los emigrantes del Tercer Mundo y de Sur del Mediterráneo van 
a rivalizar ante las escasas posibilidades de acogida que les brindan los países europeos occidentales. Los del Norte del Mediterráneo se convierten en países de inmigración, costituyendo un foco emisor menos y un centro receptor más. Además las nuevas circunstancias reabren la corriente migratoria del Este, que para algunos países resulta más próxima, no sólo geográfica sino culturalmente, con lo que las obligaciones para con ellos se manifiestan más fuertes (Alemania reunificada). Con la caída del muro de Berlín, Europa vuelve a ser una (Chesnais, 1990-91), lo que provoca una redistribución de la población europea con la que no se había contado, dado lo imprevisible del suceso. Si bien es verdad que los países de Europa del Este no han dejado nunca de enviar población, aunque fuera de forma clandestina, hacia occidente (SOPEMI, 1992), estas nuevas circunstancias van, no sólo a aumentar los flujos, sino a acelerar el proceso (Chesnais, 1990-91) y a diversificar los destinos.

En los primeros momentos se temió una emigración de grandes proporciones, incluso en el país más cerrado hasta ese momento, la Unión Soviética. Se señalaba la posibilidad de que la población necesitara y deseara salir de su país: «el estado actual de la economía soviética, la crisis social y política general, hace pensar que esta emigración tomará un carácter masivo» (Vichnevski, A.; Zayontchkovskaia, J., 1991). Salt veía la posibilidad de una eventual emigración en masa de los países del Este hacia su «tierra prometida», es decir, hacia los países de Europa Occidental (Consejo de Europa, 1991). Incluso daba los argumentos de por qué se produciría: el tiempo que faltaba para que se concluyera la transición política y económica de los países del Este, el previsible aumento del desempleo que se produciría en ellos, la elevada proporción de población dedicada a la agricultura sin perspectivas de mejorar, que se vería impulsada a salir y la existencia de importantes conflictos étnicos, que habrían de provocar trasvases diversos.

Se pueden multiplicar las citas en este sentido en los años 91 y 92 , aunque hoy, con cierta perspectiva para analizar el fenómeno, se vea de otro modo. Autores como Chesnais, indican que se ha elucubrado con la idea de masividad de esos movimientos de población, pero señala que no han llegado a producirse, a excepción de las reubicaciones de alemanes tras la eliminación de la frontera entre las dos Alemanias, o de la reagrupación familiar de alemanes residentes en otros países de la antigua órbita soviética. Otro tanto hace Salt en el informe presentado al Consejo de Europa (Salt, J., 1993). 


\section{La historia migratoria de los paises del Este}

La historia de los movimientos migratorios de los países de la Europa central y oriental es muy antigua y cambiante, sujeta a multitud de vaivenes de tipo económico, político y social. El hecho mismo de la diversidad étnica existente en ellos sólo puede explicarse a través de movimientos de población relacionados con hechos relativamente recientes en unos casos (Guerras Mundiales), o muy antiguos en otros. Así, por citar ejemplos, en 1989 sólo el 85,3\% de los habitantes de Bulgaria, el 89,1 de los de Rumanía o el 96,6 de Hungría, eran de origen del propio país, estando el resto repartido entre grupos diversos. Este fenómeno es especialmente importante en las Repúblicas de la ex URSS, donde los naturales a menudo están en proporciones inferiores al 70\% (Moldavia el 63,9, Tajikistán el 58,8, Estonia el 64,7 o Georgia el 68,8) (Grecic, V., 1993). El caso de Yugoslavia es el más expresivo y analizado, sirviéndonos de referente principal de la historia migratoria de unos países con claras relaciones con los del Sur de Europa en el pasado. Tras un larguísimo proceso esencialmente inmigratorio, mediante el cual se fueron configurando los grupos étnicos que componen la ex Yugoslavia, el siglo XIX marca el comienzo de una etapa de signo emigratorio, que quedaría como una constante. En 1830 comienza a hacerse significativa la presencia de eslavos del Sur en América y el Pacífico. La mala situación económica provocó un empobrecimiento de los campesinos, que no encontraban acomodo en las ciudades débilmente industrializadas, por lo que comenzó una emigración con destino a Estados Unidos, Argentina, Chile e incluso Australia y Nueva Zelanda. Fue una migración económica, de jóvenes desposeídos, que trabajaron como leñadores, pescadores, agricultores y ganaderos, en situación muy difícil. A comienzos de siglo se calcula que salieron en torno a 800.000 sudeslavos con destino a USA, donde trabajaron en la construcción del ferrocarril y como mineros en California (Banovic, D., 1990). El período de entreguerras fue también emigratorio. Tras la primera Guerra el nuevo Reino de Yugoslavia no resolvió sus problemas económicos, ni los de nacionalidad, dando a la emigración justificación política. Siguieron saliendo gran número, si bien entonces las cuotas de USA impulsaron la corriente hacia Argentina y Brasil y dentro de Europa, a Francia (Cacic-Kumpes, J., y Kumpes, J., 1990). En torno a 1930, aunque en declive, aún eran muchos los yugoslavos emigrados. Más de 700.000 en Estados Unidos y 140.000 
en América del Sur (Banovic, 1990), en esta etapa más vinculados a la industria. Desde 1927 comenzaron a aceptar trabajos temporales en Europa y con la llegada de los nazis muchos fueron reclutados para la industria alemana (Hersak, E. y Mesic, M., 1990). El final de la II Guerra Mundial provocó importantes movimientos de población. Se calcula que de Yugoslavia salieron cerca de 300.000 militares del ejército vencido, miembros de partidos políticos vinculados al fascismo y pro-occidentales que no aceptaban el comunismo. Hubo, también, una repatriación de yugoslavos desde países como Francia (Hersak, E., y Mesic, M., 1990). Entre 1939 y 1948 emigraron alrededor de 669.000 yugoslavos.

De Polonia también hubo importantes flujos migratorios antes de la I Guerra Mundial. Las mayores salidas se produjeron de 1860 a 1890, motivadas por exceso de mano de obra en la agricultura, insuficiente demanda en la industria y alta tasa de crecimiento. Se calcula que salieron más de 3,5 millones de polacos hasta la I Guerra y 1,5 millones entre 1919 y 1939, que tuvieron Estados Unidos como primer destino (1,7 millones). Hubo también en Polonia una importante migración temporal y deportaciones a Rusia entre 1864 y 1915 (Okolski, M., 1991).

Hungría fue también país de gran emigración. Entre 1899 y 1913 salieron 1,4 millones de personas hacia USA y Europa Occidental. Tras la I Guerra, unos 200.000 pasaron a Rumanía (SOPEMI, 1992). Checos y eslovacos poseen igualmente una larga tradición migratoria, desde el siglo XIX. En cambio, tras la I Guerra Mundial, con la independencia, Checoslovaquia fue testigo de una inmigración de checos y de otros orígenes y de un nuevo retorno tras la II Guerra. Por el contrario, hasta 1947 se expulsó a alrededor de 2,5 millones de alemanes (SOPEMI, 1992).

La emigración del Este en la etapa socialista. Una vez constituidas como Repúblicas Socialistas se produjo un cambio en las características migratorias de los países de esta órbita. A pesar de que la emigración fue oficialmente prohibida, se calcula que desde 1948 a 1989 al menos el 5\% de la población de Polonia, Checoslovaquia, Hungría, Rumanía y Bulgaria se perdió por emigración hacia Occidente (Greci, V., 1993). Los regímenes socialistas silenciaron la emigración, que se consideraba tema tabú y un crimen contra el estado (Chesnais, 1992). En este período, como consecuencia de la revolución socialista, la emigración fue, en bue- 
na parte, clandestina y política en todos los países del bloque, pero nunca cesó totalmente, salvo en casos puntuales, como entre 1952 y 1955 en Polonia, coincidiendo con la etapa más dura del stalinismo. Hubo también movimientos internos, como los producidos para ocupar las tierras dejadas por la salida de alemanes en Yugoslavia y el éxodo rural hacia las ciudades en que se desarrollaban planes de industrialización, que fueron masivos entre 1960-74. Así como los de musulmanes de Bulgaria a Turquía de finales de los ochenta, los alemanes de Polonia a la RFA desde 1975, los judíos rumanos a Israel en los sesenta y los soviéticos en los setenta y ochenta (Okolski, M., 1991).

Los emigrantes fueron esencialmente de tres tipos: trabajadores clandestinos o ilegales, solicitantes de asilo y refugiados según la Convención de Ginebra. El freno oficial a la emigración fue grande en todos los países, por la dificultad extrema de obtener pasaporte (sólo suavizada en algunos desde 1976 por los acuerdos de la Conferencia de Seguridad y Cooperación de Europa), por el control y limitación de obtener divisas y por la exigencia de visado a los del Este en varios países occidentales. En el caso de Yugoslavia, al ir evolucionando la economía hacia la autogestión y liberalización de parte de la producción, acompañada de ciertas libertades, se produjo la aparición del paro, lo que motivó cambios políticos que llevaron a la apertura de fronteras para la migración. Hubo una curiosa forma de migración organizada, que comenzó en 1965, tras una ley de amnistía para los emigrantes que habían salido a buscar trabajo y para los refugiados políticos. Se daba prioridad para salir a los parados y se llegaban a establecer servicios oficiales para organizar el empleo de trabajadores en el extranjero. En 1968 se firmó un acuerdo con la RFA. Así la emigración exterior fue una forma normal de empleo, estimulada para mantener la identidad cultural, aunque mal vista por los que continuaban en el país. En 1971 un censo calculaba en 763.000 los yugoslavos fuera del país, de los cuales 463.000 estaban en la RFA. Éste constituyó el cuarto grupo de emigrantes del Este: económicos, legales y con carácter temporal. En su mayoría eran jóvenes, entre 25-35 años (80\%), hombres (82\%), semicualificados (50\%) y muy considerados por su disciplina (Cacic-Kumpes, J., y Kumpes, J., 1990), con un perfil no muy diferente al de los emigrantes mediterráneos que, desde años antes salían a los países más industrializados. Después de 1972 se replanteó el tema de las migraciones y se puso el acento en el retorno, con la promulgación de varias leyes que concluyeron en 1976. A 
partir de entonces predominó un retorno de personas mayores, con poca cualificación y muchos problemas, a los que la propaganda presentaba como «capitalistas» (Hersak, E., y Mesic, M., 1990).

No hubo nada parecido en los restantes países del Este. Hungría se mantuvo totalmente aislada en la etapa socialista, exigiendo para emigrar la reunificación familiar y el visado de entrada en el país de destino, sin embargo hubo grandes oleadas de salida. Una tras la revolución y otra tras la intervención soviética en 1956. En este año había casi 185.000 refugiados húngaros y en Austria solicitaron asilo 180.000. En Checoslovaquia desde mediados de los cincuenta a los ochenta siempre hubo más salidas que entradas. Legalmente salían de 2 a 5.000 personas por año, con un estricto control policial y necesariamente con la condición de reagrupamiento familiar, o con un empleo autorizado. Ilegalmente salían más, en torno a 5-7.000 personas. Emigraban a Austria, Alemania, Francia, USA, Canadá y a otros países del bloque (Hungría, Polonia y la ex URSS). Hubo un momento clave entre 1965-70, con un aumento de salidas que culminó con la masiva, tras la invasión de las tropas del Pacto de Varsovia, que puso fin a la «primavera de Praga» en 1968, tras de lo cual se cerró la frontera. Salieron sobre 20.000 legales y 70.000 ilegales, la mayoría jóvenes, muy cualificados, que se dirigieron a Austria, Alemania, Suiza, USA y Canadá. Eran disidentes del régimen, perseguidos por el partido comunista y miembros del mismo que habían participado activamente en las reformas, además de profesionales muy afectados en sus intereses económicos por las políticas de empleo y medidas igualitarias. De 1970 a 1980 la emigración se hizo muy difícil, sumando unos 40.000 en toda la década entre legales e ilegales.

Un aspecto a considerar es la importancia de la denominada «fuga de cerebros» principalmente entre refugiados. El muro de Berlín se levantó en 1961 por la RDA para frenar la sangría que suponía aquélla. Entre la clase académica y los profesionales más cualificados hubo una gran oposición al régimen, ante su pérdida de oportunidades reales. Tras cada conmoción política aumentaba el número de intelectuales que emigraba. Especialmente significativos fueron los casos de alemanes de la RDA a la RFA, polacos a Estados Unidos y judíos hacia Israel y USA (Rhode, B., 1993). En la situación actual sigue siendo importante el volumen de emigrantes con alta cualificación, aunque ya no encuentran tantas oportunidades. Han significado una importante pérdida durante mucho tiempo. Hoy hay una nueva permeabilidad, de modo que se bus- 
ca la salida de titulados a mejorar su formación, aunque muchos no retornan. Se trata de aprovechar e incentivar el retorno de los más cualificados y se inicia el traslado de profesionales y titulados occidentales que acuden al Este a mejorar la preparación de los del país, en la compleja transición a la economía de mercado.

El ocaso del sistema 1980-1089. En torno a 1980 comienza una nueva etapa, coincidiendo con la crisis en Europa, que desembocó en una serie de cambios en la política de inmigración sustanciados en un cierre de fronteras y modificación de las leyes de asilo y refugio. Se hace más fácil obtener pasaporte para los ciudadanos del Este, aunque siguió siendo difícil obtener divisas. La política de visados fue fundamental. Los países del Oeste no favorecieron la inmigración del Este, en cambio, aún era fácil de obtener la consideración de refugiados e incluso quedarse como residentes, realizando trabajos despreciados por los naturales del país (Gwiazda, A., 1992). Las cifras oficiales de salida en el perído 18089 son muy bajas, pero no responden a la realidad, como se confirma al analizar los datos en los países de acogida. El cuadro I da una idea aproximada de la situación. En este período sólo la RFA acogía a un número considerable en relación con la política de propiciar la inmigración de alemanes de origen.

La tipología de flujos de este período comprende siete casos, según Okolski:

- Una parte pequeña se reclutados legalmente como inmigrantes (yugoslavos por acuerdos gubernamentales).

- Reunificación familiar con familiares en las fronteras próximas, o con algún miembro que lograban asentarse en un país lejano.

- Retorno de minorías étnicas, en los años ochenta, alemanes de Polonia, Rumanía y la URSS, musulmanes de Bulgaria y judíos de la URSS.

- Refugiados, sobre todo a Austria e Italia.

- Los que acuden, tras un matrimonio mixto al país de origen del cónyuge ( $10 \%$ en el caso de Polonia).

- Salida a un país de inmigración donde hubiera familiares.

- Solicitud de residencia en un país sin relación previa.

A pesar de la importancia que en este período tuvo la búsqueda del asilo político, aún relativamente fácil de obtener por la adecuación 
CUADRo I

MIGRACIÓN DEL ESTE EN OCCIDENTE (1991)

\begin{tabular}{|c|c|c|c|c|c|}
\hline \multirow{2}{*}{ País de origen } & \multicolumn{5}{|c|}{ País de destino } \\
\hline & $\begin{array}{c}\text { RFA } \\
\text { (1) }\end{array}$ & $\begin{array}{c}\text { Austria } \\
\text { (2) }\end{array}$ & $\begin{array}{c}\text { Suecia } \\
\text { (3) }\end{array}$ & $\begin{array}{c}\text { Francia } \\
\text { (4) }\end{array}$ & $\begin{array}{l}\text { UK } \\
\text { (5) }\end{array}$ \\
\hline Bulgaria & - & 0,7 & - & - & 0,1 \\
\hline Checoslovaquia & 18,1 & 14,8 & - & 0,4 & 0,2 \\
\hline Hungría & 13,6 & 12,8 & - & 0,7 & 0,3 \\
\hline Polonia & 321,1 & 37,3 & 11,8 & 5,6 & 2,2 \\
\hline Rumanía & 107,0 & 7,7 & - & 3,3 & 0,1 \\
\hline URSS & 25,4 & 0,1 & 1,1 & 0,2 & 0,2 \\
\hline Yugoeslavia & 51,7 & 1,7 & 0,6 & 1,0 & 1,0 \\
\hline Total 7 países & $\begin{array}{c}483,2 \\
(536,9) \\
(2)\end{array}$ & 75,1 & 14,5 & $\begin{array}{c}11,2 \\
(7,9) \\
(4)\end{array}$ & 4,1 \\
\hline
\end{tabular}

Fuente: Okolski, M.: «La nouvelle donne migratoire en Europe de l'Est», vol. 7, n. ${ }^{\circ} 2$, 1991, p. 13. (1) Inmigración neta, (2) No comprendida Yugoslavia, (3) Sólo solicitantes de asilo, (4) Excluidos los solicitantes rechazados, (5) Sólo los autorizados a establecerse.

con los requisitos de la Convención de Ginebra, multitud de trabajos muestran que ya en esta etapa la decisión de emigrar se toma por razones económicas (Okolski, M., 1991).

Los movimientos migratorios desde 1989. A partir de 1989 se inicia la última etapa en la historia de las migraciones del Este, que continúa hasta el presente y que se abrió con tintes de gran expectación. En una demostración de la dificultad de hacer previsiones, no se han cumplido las más alarmantes de avalancha de población e, incluso, desde 1993 se ha iniciado un descenso con cambios importantes. Además de la ralentización de la emigración hacia Occidente, los rasgos a destacar en el panorama migratorio del Este son: el incremento de los movimientos intrarregionales, la inversión del saldo migratorio en algunos países, o al menos el desarrollo de una inmigración, así como 
la transformación lugar «de paso» para migrantes que tienden a un tercer destino, el aumento de la migración de carácter temporal y el descenso del número de demandantes de asilo y refugio en Occidente (SOPEMI, 1993, 1997).

El incremento de movimientos regionales se debe en parte a las tensiones sociales y étnicas, sobre todo tras la fragmentación de la URSS y Yugoslavia y a la presencia de minorías étnicas originarias de países y regiones vecinas. Afecta a alemanes de origen en Polonia, Hungría, Rumanía y ex URSS, húngaros en Rumanía y República Eslovaca, polacos en Ucrania, Kazastán y Siberia, rusos en los estados Bálticos, griegos en la región póntica y turcos en Bulgaria. Aunque la emigración sigue siendo dominante, la inmigración comienza a ser importante, hasta el extremo de que ya en algunos países supera a la primera. Aún hoy no es posible evaluar con exactitud los movimientos migratorios en los países del Este, donde a pesar de los esfuerzos por desarrollar nuevos métodos de control, actualización de terminología y armonización con las políticas occidentales, los datos no son, ni todo lo buenos que se requiere, ni totalmente comparables, amén de existir un alto volumen de clandestinos. No obstante, parece que la República Checa y Hungría son los que reciben mayor número de extranjeros, seguidos por Polonia y Bulgaria. Se trata de flujos regionales y de lejano origen, como vietnamitas, chinos y de Oriente Medio, a los que se suma personal muy cualificado de países occidentales y retornados. En este nuevo fenómeno hay que mencionar que en muchas ocasiones se trata de migrantes «de tránsito» que tienen como objeto el «salto» a Alemania, Austria o Suecia y utilizan los estados fronterizos, a los que entran como turistas, estudiantes y por negocios y se quedan de forma irregular, proceden de Turquía, Albania, ex Yugoslavia, Bangladesh, India e Irán y trabajan en una recién desarrollada economía sumergida.

Mientras que se constata un descenso de la emigración permanente, es de destacar el auge de la temporal de trabajadores estacionales, fronterizos, individual y con contrato entre países del Este y de la OCDE, o entre los primeros. Domina entre polacos en Alemania y Austria, e incluso en Francia, Rep. Checa y Suecia. En 1995, la mayoría de los polacos con empleo temporal se amparaban en acuerdos gubernamentales. Dadas las medidas tomadas por los países de la OCDE para restringir las concesiones de asilo y refugio, al considerar que hoy los países del Este son «seguros» y sus habitantes no precisan de asilo, este 
grupo es cada día menos importante. Caso aparte es el de la ex Yugoslavia, en situación de guerra durante largo tiempo, que dio lugar a salida de ciudadanos que buscaban asilo. Desde 1992 varios países exigieron visado a los procedentes de la ex Yugoeslavia y les denegaron el refugio, sustituyéndolo por un «estatuto de residencia temporal por razones humanitarias». Excepto en este caso, en general decrece el número de demandantes de asilo, antes las escasas concesiones y se firman acuerdos entre países de la OCDE y del Este para readmitir a los solicitantes rechazados y a los irregulares en el marco de la cooperación internacional. Actualmente las motivaciones de los migrantes del Este son esencialmente económicas (Okolski, M., 1991; Gwiazda, A., 1992; Hövekopp, E., 1993; Vichnevski, A., 1991; SOPEMI, 1995, 1997...) sin olvidar el peso que tienen las razones de carácter cultural en la salida de minorías étnicas hacia sus zonas de origen. Como rasgos finales podriamos apuntar la existencia de salidas de personas del Este a Occidente con carácter temporal, para lograr una cualificación en las nuevas tecnologías, aprendizaje de idiomas y el retorno de antiguos emigrados que motiva el desarrollo de una política de retorno.

\section{La migración del Este en la España actual}

La dificultad de contabilizar los efectivos. Los primeros residentes en España procedentes de los países del Este se reducen a un pequeño número de refugiados que se instalan en nuestro país en la etapa de la dictadura, que los acoge. Antes, la nobleza perseguida tras la Revolución de 1917, se refugiaba en algunos países de Europa Occidental y entre ellos en España. Fueron pocos los que acudieron a nuestro país como consecuencia de las dos guerras mundiales, quedando como testimonio de aquellos desplazamientos. El censo de 1991, que recoge la fecha de entrada de los registrados, contabiliza como llegados a España antes de 1960 a 100 personas de nacionalidades del Este, a los que habría que añadir los que hubieran obtenido la nacionalidad española. Este grupo supone, tan sólo, el 1,5\% del total de los censados. Entre 1960 y 1979 llegaron un $4,3 \%$ del total, mientras que el $94,1 \%$ restante llegaba en la década 81-91 y, en gran medida, en los tres últimos años.

En las estadísticas españolas hasta el Censo de 1981, los ciudadanos del Este aparecían englobados en «otras procedencias», dado su escaso 
número. Sin embargo, en el Censo de 1991 están ya diferenciados, lo que refleja el aumento y significación de sus llegadas en los años precedentes. Entre 1985, fecha de entrada en vigor de la «ley de extranjería» y 1994 la cifra se multiplica por diez (cuadro II), aunque son los años posteriores a la caída del muro de Berlín los que presentan mayor incremento. Pasan del 0,6\% del total de trabajadores extranjeros residentes en 1989 al 2,2\% en 1994 . De entre todas las procedencias es Polonia la que posee mayor número, proporción y crecimiento, pero también las ex Yugoslavia y ex Unión Soviética junto a Rumanía y Bulgaria ven aumentar cosiderablemente sus contingentes.

En ningún caso pretendemos contabilizar las cifras exactas de inmigrantes del Este en España. Como en cualquier estudio de migraciones es extremadamente difícil conocer dicho número. Cada fuente se refiere a una parte del total, sin que sean excluyentes. Además las cifras sufren constantes variaciones, pues son muchos los que retornan o emigran a un nuevo destino. También oscila el número en función de la adquisición o pérdida de su situación de regularidad y nacionalidad. En el último censo (1991), el número de residentes nacidos en los países del Este era de 4.450 personas y el de igual nacionalidad era de 3.412, presumiblemente por el proceso de nacionalización realizado sobre

CUADRO II

EXTRANJEROS RESIDENTES EN ESPAÑA CLASIFICADOS POR NACIONALIDAD. EVOLUCIÓN DE 1985 A 1994

\begin{tabular}{lrrrrrrrrrr}
\hline País & $\mathbf{8 5}$ & $\mathbf{8 6}$ & $\mathbf{8 7}$ & $\mathbf{8 8}$ & $\mathbf{8 9}$ & $\mathbf{9 0}$ & $\mathbf{9 1}$ & $\mathbf{9 2}$ & $\mathbf{9 3}$ & $\mathbf{9 4}$ \\
\hline Hungría & 52 & 92 & 125 & 160 & 178 & 188 & 297 & 214 & 214 & 208 \\
Polonia & 297 & 363 & 422 & 495 & 675 & 613 & 3.122 & 2.167 & 3.724 & 3.320 \\
Rumanía & 89 & 114 & 138 & 142 & 176 & 179 & 566 & 664 & 883 & 1.028 \\
URSS & 122 & 142 & 191 & 239 & 291 & 402 & 753 & 1.023 & 1.437 & 1.668 \\
Yugoslavia & 155 & 203 & 269 & 295 & 384 & 416 & 421 & 565 & 937 & 1.216 \\
Otros & 382 & 477 & 547 & 632 & 767 & 822 & 1.125 & 2.160 & 2.476 & 2.679 \\
Total EE & 1.103 & 1.391 & 1.692 & 1.963 & 2.471 & 2.620 & 6.284 & 7.973 & 9.671 & 10.119 \\
T. Europa & 158.211 & 118.528 & 216.116 & 234.036 & 259.474 & 270.022 & 180.446 & 197.790 & 218.397 & 238.507 \\
T. Mundo & 241.971 & 293.208 & 334.935 & 360.032 & 398.147 & 407.647 & 360.655 & 393.100 & 430.422 & 461.364 \\
\hline
\end{tabular}

Fuente: Anuario Estadístico, 1995. INE. 
todo por los que llegaron antes, lo que evidencia un problema inicial a la hora de estudiar el colectivo. Los permisos de trabajo concedidos en 1992 fueron 5.831, cifra muy superior a la de censados, a pesar de que no incluye menores de edad ni inactivos. Otras cifras a considerar son los 4.737 permisos concedidos en el proceso de regularización llevado a cabo entre 1991-92. En 1994, la Dirección General de la Policía, cifraba en 10.449 los residentes del Este. En las propias Embajadas y Consulados calculan que la cifra real de inmigrantes, muchos clandestinos, puede estar en torno a las 40.000 personas, dado el ritmo de llegada posterior a 1991. Un ejemplo expresivo de la dificultad de conocer el número real es el caso de los de origen búlgaro, que en el censo del 91 eran 239 por nacimiento y 214 por nacionalidad, obtuvieron 546 permisos de trabajo en 1992 y 635 en 1993, mientras que en las fichas consulares hasta 1995 están registrados 1.357. Estas cifras no parecen justificar la antes comentada alarma que se produjo ante la posibilidad de una «avalancha» de ciudadanos del Este tras la caída del muro, pero son expresivas en relación a nuestro país de reciente inmigración, por su novedad y por su cuantía. En los primeros años el incremento fue relativamente rápido, pero desde 1993 se aprecia en la mayoría de estas nacionalidades un incipiente descenso de efectivos, que coincide con el que se da en otros países de acogida, por la mejora de las condiciones económicas de algunos de los países de origen y por la implantación de contingentes de entrada en España, donde la oferta no se adapta bien a sus necesidades.

Características del grupo de inmigrantes del Este en España. A partir de dos fuentes oficiales españolas podemos trazar el perfil de este grupo de inmigrantes, así como analizar sus contrastes internos por nacionalidades. La entrevista personal y la información obtenida a través de embajadas y Asociaciones de Inmigrantes, junto a la aparición de noticias de prensa y opiniones de los españoles, nos completan dicho perfil, con aspectos más subjetivos. En los datos del Censo de 1991 los hechos que destacan son:

- El notable equilibrio por sexo, que en el conjunto es de casi un $50 \%$ para cada uno, si bien con contrastes por países. Polacos y rumanos tienen un predominio de varones (más del 54\%), mientras que entre los rusos y húngaros son las mujeres mucho más numerosas (menos del $44 \%$ son varones). También llama la atención el contraste entre los na- 
cidos en países del Este y los que poseen la nacionalidad de estos países. Sólo el 77\% de los nacidos poseen una de estas nacionalidades, lo que puede explicarse por el aumento de las nacionalizaciones y por el creciente número de matrimonios mixtos que se realizan, sobre todo entre las mujeres y son una prueba del proceso de integración. Los húngaros de ambos sexos y sobre todo las checoslovacas son los que mayor contraste muestran entre nacidos y nacionalizados. Las pirámides de población son bastante contrastadas. Aparte de mostrar el predominio de uno de los dos sexos en algún caso, destaca el grado de envejecimiento de las de Hungría, Checoslovaquia y la URSS; el alto número de jóvenes varones de Polonia y Rumanía y la escasez de niños en todas ellas, salvo Bulgaria. Aunque predominan los casados, también es de destacar el alto número de solteros entre los varones polacos, búlgaros y rumanos y el de separados y divorciados varones en Hungría y Checoslovaquia y mujeres de Bulgaria.

- El buen nivel de instrucción que poseen (Cuadro III). Considerada la población de más de diez años, hay una mayoría que tiene al menos estudios de segundo grado y enseñanzas medias. Salvo en el caso de los de la URSS, más del 40\% tienen este nivel. Pero aún es más sorprendente el

CuAdro III

NIVEL DE INSTRUCCIÓN POR NACIONALIDAD. POBLACIÓN DE MÁS DE DIEZ AÑOS. CENSO 1991 (\%)

\begin{tabular}{|c|c|c|c|c|c|c|c|c|}
\hline \multirow{2}{*}{ País } & \multicolumn{2}{|c|}{$\begin{array}{c}\text { Analf. } \\
\text { s. e. }\end{array}$} & \multicolumn{2}{|c|}{$1 .^{e r}$ grado } & \multicolumn{2}{|c|}{$\begin{array}{l}2 .^{\circ} \text { grado } \\
\text { y medias }\end{array}$} & \multicolumn{2}{|c|}{$\begin{array}{c}3 .^{\text {er }} \text { grado } \\
\text { y super. }\end{array}$} \\
\hline & $\mathbf{H}$ & $\mathbf{M}$ & $\mathbf{H}$ & $\mathbf{M}$ & $\mathbf{H}$ & $\mathbf{M}$ & $\mathbf{H}$ & $\mathbf{M}$ \\
\hline Bulgaria & 5,4 & 3,5 & 9,7 & 5,8 & 39,8 & 40,7 & 45,2 & 50,0 \\
\hline Checoslova. & 4,3 & 7,6 & 20,0 & 17,3 & 44,3 & 44,2 & 31,3 & 32,7 \\
\hline Hungría & 5,5 & 8,8 & 11,1 & 12,1 & 44,4 & 47,2 & 38,9 & 31,9 \\
\hline Polonia & 6,9 & 5,8 & 14,6 & 12,4 & 57,8 & 43,9 & 26,0 & 37,9 \\
\hline Rumanía & 5,1 & 2,4 & 11,8 & 11,2 & 44,8 & 51,5 & 38,1 & 34,9 \\
\hline URSS & 8,6 & 6,2 & 13,6 & 14,0 & 35,2 & 32,7 & 42,6 & 47,1 \\
\hline Yugoslavia & 5,2 & 9,5 & 11,7 & 13,6 & 44,8 & 39,4 & 38,3 & 37,4 \\
\hline
\end{tabular}

Fuente: Censo de la Población Española, 1991. 
alto porcentaje de personas con estudios universitarios, que suponen siempre más del $30 \%$ y hasta cerca del $50 \%$ en los procedentes de la URSS. Por sexo es incluso mayor el número de mujeres con alto nivel de instrucción. Los índices de analfabetismo y de personas sin estudios son mínimos. El nivel de estudios está muy por encima de la media de los inmigrantes, incluso a nivel superior a muchos de los países más desarrollados y muy destacado en relación a los países pobres. También se aprecia que los hijos están cursando estudios de segundo grado y universidad en proporción muy elevada.

- La profesión declarada presenta un alto índice de profesionales, técnicos y similares, que salvo entre los polacos, con sólo un $30 \%$, siempre está por encima del 50 y hasta del $60 \%$ de la población. Frente a la escasísima o nula presencia de trabajadores de agricultura, ganadería y pesca, hay que hacer notar algunos elevados porcentajes de directivos (7-10\% entre yugoslavos y checos). Hay un alto número de empleados en la construcción, que siendo siempre más del $10 \%$, entre los checos y sobre todo los polacos, llega a sobrepasar el 30\%. Los administrativos son numerosos entre yugoslavos, rusos y checos. En servicios personales y hostelería, con grandes contrastes, destacan yugoslavos, polacos y húngaros.

- La mayoría trabaja como asalariados en más del $81 \%$ salvo entre los rusos y yugoslavos que, en contraposición, cuentan con empresarios con y sin asalariados. En general es un hecho a destacar el alto porcentaje de empresarios en relación a otros colectivos de inmigrantes. También resulta expresivo como signo de estabilidad e integración, que de los asalariados de Rumanía, Hungría, Checoslovaquia y Bulgaria sean fijos más de la mitad. En cambio, entre polacos y rusos hay mayor proporción de eventuales. Las empresas en las que trabajan son predominantemente de servicios (casi siempre más del 50\%). Polacos y checos, en cambio, trabajan en alto número en la construcción y todos, salvo los húngaros, al menos en un $10 \%$, se dedican a empresas industriales manufactureras.

- A pesar de este panorama tan favorable en lo relacionado con la instrucción y profesión, la relación con la actividad económica presenta, por un lado, una elevada proporción de población inactiva, que llega a superar el $50 \%$ entre checoslovacos y húngaros y que siempre supera el $40 \%$ y, por otro, altas tasas de paro. La población no activa está formada sobre todo por mujeres dedicadas a sus labores, pero como co- 
rresponde a la composición por edades y a la existencia de grupos de antiguo asentamiento, también presenta altos índices de jubilados y pensionistas y de jóvenes cursando estudios. Lo más destacable, no obstante, es la fuerte incidencia del paro en esta población. Considerando todo el grupo (parados que han trabajado antes y los que están a la busca del primer empleo) los valores son muy elevados. Salvo en el caso de Yugoslavia, siempre está muy por encima de la cifra de España (en 1992, el 22,8\%) llegando a la alarmante del 45,7\% en el caso de Rumanía. Considerado según el sexo, el porcentaje de actividad es muy contrastado (cuadro IV). En cualquier caso son valores más elevados que los de la población española que posee mayor proporción de ancianos en su composición (63-36, 5\% respectivamente). El paro afecta también de distinta forma a hombres y mujeres. Tan sólo las polacas y yugoslavas presentan menor tasa de paro que los varones (es de destacar la facilidad de las polacas para obtener empleo en el servicio doméstico). Para el conjunto español en 1995 el paro masculino era del 18,1\% y el femenino el 32,2\%, en 1991 para los inmigrantes del Este la proporción era similar, pero con valores en general más elevados, especialmente entre los rumanos, polacos y rusos.

Cuadro IV

TASA DE PARO POR NACIONALIDAD. POBLACIÓN DE MÁS DE 16 AÑOS (\%)

\begin{tabular}{lcccc}
\hline \multirow{2}{*}{ País } & \multicolumn{2}{c}{ Hombres } & \multicolumn{2}{c}{ Mujeres } \\
\cline { 2 - 5 } & $\begin{array}{c}\text { Activos } \\
\text { (1) }\end{array}$ & $\begin{array}{c}\text { Parados } \\
\text { (2) }\end{array}$ & $\begin{array}{c}\text { Activos } \\
\text { (1) }\end{array}$ & $\begin{array}{c}\text { Parados } \\
\text { (2) }\end{array}$ \\
\hline Bulgaria & 71,9 & 23,7 & 39,2 & 35,4 \\
Checoslovaquia & 61,3 & 19,1 & 33,7 & 32,3 \\
Hungría & 55,1 & 18,4 & 42,2 & 28,5 \\
Polonia & 74,6 & 33,8 & 43,2 & 32,9 \\
Rumanía & 75,0 & 42,8 & 44,3 & 51,4 \\
URSS & 73,1 & 33,0 & 42,2 & 43,0 \\
Yugoslavia & 75,7 & 18,8 & 37,2 & 17,7 \\
\hline
\end{tabular}

Fuente: Censo 1991. (1) porcentaje en relación al total población de ese sexo. (2) porcentaje en relación a los activos. 
Los registros de permisos de trabajo son una fuente de inestimable valor para completar las características de los trabajadores extranjeros en activo y constatar el carácter económico de esta migración. Partiendo de esta fuente, que hemos estudiado en los años 1992, 1993 y 1995, las conclusiones que se pueden obtener se resumen en las siguientes:

- En el conjunto de inmigrantes predomina los de 25 a 54 años, al igual que entre los procedentes de Europa central y oriental, pero, mientras que los menores de 25 años son numerosos entre otras nacionalidades de países pobres, entre los europeos del Este apenas tienen significación. Entre ellos existen también algunas diferencias, Albania, y en el último año estudiado Hungría, no tienen ningún representante por debajo o encima del grupo citado. Los de más de 55 años sólo tienen algún significado entre los que provienen de la antigua URSS. El grupo de 20-24 años sólo destaca entre polacos y rumanos.

- En conjunto, entre todos los trabajadores extranjeros residentes en nuestro país, predominan los varones, con una proporción de dos hombres por mujer aproximadamente. Esa proporción crece hasta 2,5 en los de países del Este. Por el contrario, los de la EFTA presentan una proporción de 1,3 hombres por mujer. Si se observan de forma individual las diferentes nacionalidades de centro y este de Europa, las proporciones varían entre el máximo de los checoslovacos (5,3 hombres/mujer) al mínimo de los húngaros $(1,6 \mathrm{~h} / \mathrm{m})$. Húngaros y soviéticos, además de presentar mayor equilibrio entre los sexos, muestran mayor proporción de mujeres con el paso del tiempo.

- La dependencia laboral presenta también diferencias. Mientras que la relación de cuenta ajena/cuenta propia es, de forma global, alrededor de 5 a 1, los procedentes de los países de la EFTA presentan una relación de 1,6 a favor de la cuenta ajena, a gran distancia de los de Europa del Este, en los que la proporción aumenta hasta un 16,3. Dicha cifra oculta grandes diferencias entre el máximo de Checoslovaquia ( 49,8 a 1) y el mínimo de Hungría (12,6 a 1). En conjunto, los húngaros son los que tienen mayor proporción de trabajadores autónomos.

- La duración del permiso de trabajo solicitado abunda en el significado de su integración. La inmensa mayoría, siempre suman más del 
90\%, obtienen permisos por un año o un año renovable; húngaros y soviéticos presentan proporciones de algún significado en los contratos de nueve meses, pero son los húngaros los que muestran mayor proporción en los contratos de mayor duración, cinco años, dato que refleja mayor estabilidad en el empleo y más tiempo de residencia en España, por tanto, mayor integración.

- El sector de actividad ofrece también diferencias dignas de mención. Mientras que en el total de inmigrantes la proporción de los que trabajan en el sector agrario es superior al 10\%, en los de Europa del Este es tan sólo el 3,1\%, superior, no obstante, a la del grupo de la EFTA, que es el $2 \%$. Además entre ellos existen diferencias. Mientras que los checoslovacos no llegan al $1 \%$, los polacos y rumanos casi alcanzan el $4 \%$. Entre todos los sectores, es el de servicios el que presenta un mayor número de permisos en el conjunto de extranjeros y también entre los del Este. En cambio, destaca la importancia que tienen, sobre todo los checoslovacos, en la construcción y en la industria a diferencia de otros grupos.

- La ocupación es, con el nivel de instrucción, que vimos en el análisis del Censo, la característica que más les diferencia de otros grupos de inmigrantes extranjeros del Tercer Mundo y más les asemeja a los del mundo desarrollado. En conjunto, los profesionales y técnicos son, entre los europeos del Este, más numerosos, lo que confirma su mayor preparación. Junto a ellos, en todos los países aparece también un elevado porcentaje de trabajadores de la minería. La tercera ocupación más numerosa es la de los trabajadores de servicios personales o similares, hecho que es común con la mayoría de trabajadores extranjeros. La antigua URSS, CEI, es la que presenta mayor proporción de profesionales y técnicos, seguida de los procedentes de Hungría y de la ex Yugoslavia. Checoslovacos, polacos y rumanos, presentan, sin embargo, su máximo entre los trabajadores de la minería. Conforme pasan los años se observa un incremento en la proporción de trabajadores empleados en los servicios personales y similares, ya que los llegados más recientemente tienen que trabajar en los puestos de trabajo de mayor demanda en la sociedad española actual.

Las estadísticas nos muestran el perfil más cuantificable de estos inmigrantes que presentan rasgos comunes con otros colectivos y que, dentro de una cierta homogeneidad, revelan diferencias internas poco 
importantes y a menudo relacionadas con los distintos tamaños de sus poblaciones. Lo más destacable a considerar es: su elevado nivel de instrucción, su actividad en industria, minería y servicios personales, la elevada proporción de directivos y técnicos, la acusada incidencia del paro y la elevada proporción de trabajadores masculinos y por cuenta ajena. Por tanto, comparten un nivel de instrucción, preparación profesional y ocupación con los procedentes de países del mundo más desarrollado, y por otro lado, el bajo nivel de vida que poseen los países de los que proceden, les hace participar de algunas de las características propias del Tercer Mundo.

Pese a haber significado en el pasado reciente la emigración política por excelencia en Occidente, hoy es claro que se trata de una emigración esencialmente económica. No obstante, siguió siendo considerable el número de solicitantes de asilo y refugio procedentes del Este durante un tiempo, pero las restricciones impuestas de acuerdo con el proceso generalizado en toda Europa, no sólo las concesiones, sino también el número de solicitantes, ha ido descendiendo progresivamente.

\section{CuADro V}

SOLICITANTES DE ASILO DE PAÍSES DEL ESTE 1988-1996

\begin{tabular}{lcccccccc}
\hline \multirow{2}{*}{$\begin{array}{c}\text { País } \\
\text { de origen }\end{array}$} & \multicolumn{2}{c}{$\mathbf{1 9 8 8}$} & \multicolumn{2}{c}{1990} & \multicolumn{2}{c}{1993} & \multicolumn{2}{c}{1995} \\
\cline { 2 - 9 } & v.a. & $\%$ & v.a. & $\%$ & v.a. & $\%$ & v.a. & $\%$ \\
\hline Polonia & 2.086 & 46,2 & 3.279 & 37,9 & 602 & 4,8 & 37 & 0,6 \\
Rumanía & 121 & 2,7 & 344 & 4,0 & 1.478 & 11,7 & 1.251 & 22,1 \\
Bulgaria & - & - & 290 & 3,4 & 214 & 1,6 & 48 & 0,8 \\
Checoslovaquia & 141 & 3,1 & - & - & - & - & - & - \\
Ex Yugoslavia & - & - & - & - & 710 & 5,6 & 128 & 2,2 \\
Hungría & 100 & 2,2 & - & - & - & - & - & - \\
Ex URSS & - & - & - & - & - & - & 192 & 3,4 \\
Total mundo & 4.516 & 100 & 8.647 & 100 & 12.615 & 100 & 5.678 & 100 \\
\hline
\end{tabular}

Fuente: Oficina de Asilo y Refugio. Ministerio de Interior. 
La realidad invisible en las estadísticas. Las fuentes oficiales no muestran toda la realidad que debe ser buscada a través del conocimiento directo y actual de los protagonistas. En el presente, se mantienen muchas de las razones antes expuestas para que continúe el flujo de emigrantes del Este. En los inicios de la década de los noventa, como se puso de manifiesto en el informe realizado por una comisión de la Comunidad Europea, la economía de lo que se dio en llamar los seis (Polonia, Yugoslavia, Rumanía, Checoslovaquia, Hungría y Bulgaria) presentaba numerosos problemas, que se pueden concretar, a grandes rasgos, en: un elevado grado de industrialización y alto porcentaje de empleo industrial, pero constituido por un sector obsoleto y en grave crisis por la transición de la economía planificada hacia la de mercado, con una situación añadida de grave deterioro medioambiental, elevados porcentajes de empleo en el sector agrario ( 30 y $29 \%$ respectivamente en Polonia y Rumanía, cuando la media de los Doce era de $8 \%$ ), un inadecuado desarrollo del sector de servicios de producción, además de unas infraestructuras de transporte y comunicaciones anticuadas y que debían soportar una sobrecarga, amén de tremendos desequilibrios regionales, debidos a la concentración del desarrollo en ejes complejos y aglomeraciones industriales y urbanas, que relegaban a las regiones periféricas al subdesarrollo (Comisión de las Comunidades Europeas, 1991).

Diversas encuestas llevadas a cabo en Polonia y la URSS mostraban en la población grandes deseos de emigrar, inducidos por las elevadas tasas de paro (dos millones de desempleados en Polonia en 1991) la escasez de viviendas (sólo el $11 \%$ de jóvenes casados disponían de ella), el cierre de fábricas y las pocas perspectivas de empleo, además del deterioro sufrido en sus niveles de vida (el $77,7 \%$ de los científicos encuestados en la URSS ponía este problema como el más importante) y la inestabilidad económica.

España se mantiene y hasta aumenta su poder de atracción para estas poblaciones, a pesar de que de acuerdo con las fuentes oficiales, desde el año 1993 se inicia un descenso de los solicitantes de permisos de trabajo, coincidiendo con lo que ocurre en otros países de acogida. No obstante, en la realidad lo que se detecta es un aumento de llegadas, constituidas ahora sobre todo por irregulares. Estos nuevos inmigrantes no recogidos en las estadísticas presentan, además, rasgos diferentes de los hasta ahora vistos. A través de entrevistas en profundidad a los 
propios inmigrantes y a los representantes de las organizaciones que los acogen hemos esbozado una semblanza de los mismos. El flujo actual está constituido por grupos contrastados. Uno es el reflejado en las estadísticas, compuesto por familias, a veces llegadas por la vía de la reagrupación familiar, de buen nivel cultural, que trabajan como técnicos, en algunos casos en el marco de las nuevas relaciones comerciales surgidas entre España y algunos de estos países (muy notables con la República Checa y Polonia), con toda la diversidad que vimos al analizarlos. Además se observa que emerge un nuevo tipo de inmigrante compuesto por personas cada vez más jóvenes, que acuden solos, chicos y chicas, con nivel cultural bajo y hasta muy bajo, que ni siquiera intentan la regularización, ni solicitan refugio y, muchas veces, vienen de forma clandestina por la vía del turismo, que está en auge entre los habitantes de España y los países del Este y propicia un mutuo mejor conocimiento. Estos jóvenes sienten gran atracción por el mundo occidental, que cada vez conocen mejor por los medios de difusión y por los anteriormente emigrados y en concreto valoran muy positivamente España por diversas razones, al considerar que es un país tolerante y divertido, con buen clima, relativamente próximo, menos caro que otros desarrollados del entorno y con facilidades para encontrar empleo sumergido, aunque sea en trabajos de categoría inferior a su preparación. Salen de su país con una motivación económica clara, al tener grandes dificultades para encontrar allí trabajo, sobre todo en áreas donde se están produciendo cierres de empresas que llevan a mucha población al paro (como recientemente en la región de Mielec, en Polonia), pero también con un cierto afán de aventura, de conocer otras realidades, para luego retornar a su país. De hecho, están por períodos que no suelen sobrepasar la media de cinco años, con intención de volver desde el comienzo y ya sin pensar en utilizar España como «puente» hacia otros destinos. También se detecta la llegada de mujeres casadas, que dejan su familia por un tiempo. A menudo se relacionan intensamente entre sí, compartiendo vivienda y acudiendo a centros religiosos donde son atendidos por capellanes compatriotas (polacos y rumanos) de forma similar a los españoles que en los años sesenta emigraban a Europa del Norte.

En general son bien acogidos por la población española, mejor que otros colectivos de inmigrantes, por considerarlos serios, bien preparados, honestos, trabajadores y disciplinados (como demuestra el hecho 
de la abundancia de matrimonios mixtos y la frecuencia con la que al buscar empleo, a través de la prensa, exponen su nacionalidad junto a su profesión), a pesar de lo cual encuentran dificultades por la competencia con otros grupos de inmigrantes y por su desconocimiento del español.

En contraste con lo antedicho, en los últimos tiempos, se detecta la aparición de un pequeño grupo de ciudadanos del Este relacionado con el mundo de la mafia y de la delincuencia, del más bajo nivel cultural, a veces expulsados de otros países, como Alemania, que en palabras de los encuestados está causando graves perjuicios a la mayoría de gente honesta (en tan sólo los tres primeros meses de 1998 se registraron 109 detenciones de ciudadanos checos) dificultándoles la obtención de empleo y que colaboran a la introducción clandestina de otros compatriotas a los que extorsionan.

\section{Conclusión}

El espacio migratorio europeo ha experimentado importantes cambios en los últimos años. Un nuevo foco emisor ha surgido en los países del Este y un nuevo foco receptor en los del Norte del Mediterráneo. Aunque no se han cumplido las expectativas iniciales de «avalancha» de migrantes del Este, la importancia del flujo desde 1989 ha alcanzado a España, donde ha surgido un nuevo grupo de inmigrantes que comparte características con los procedentes del mundo desarrollado y del Tercer Mundo, poniendo de manifiesto las complejas relaciones dentro de este nuevo espacio europeo. A pesar del corto período de tiempo transcurrido desde el inicio de este flujo, ya se pueden constatar cambios en las características de la migración que corroboran la necesidad de analizar sus diversos componentes a través de fuentes no sólo cuantitativas, sino también subjetivas y cualitativas.

\section{BIBLIOGRAFÍA}

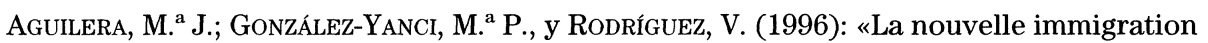
polonaise en Espagne», en Revue Européenne des Migrations Internationales, vol. 12, n. ${ }^{\mathrm{a}}$ 1. Poitiers, pp. 91-107.

BANOVIC, B. (1990): «Histoire de l'émigration yougoslave vers l'Amérique et le Pacifique», en Revue Européen des Migrations Internationals, vol. 6, n. ${ }^{2} 2$, pp. 85-96. 
CACIC-Kumpes, J., y KumPes, J. (1990): «Approche socio-historique des migrations yougoslaves en France», en Revue Européenne des Migrations Internationales, vol. 6, n. ${ }^{\circ}$ 2,1 .

COMISIÓN DE LAS COMUNIDADES EuROPEAS, (1991): «Las regiones en la década de los noventa» (cuarto informe periódico sobre la situación y la evolución socioeconómica de las regiones de la Comunidad), Luxemburgo, 114 pp.

ChesnaIs, J. C. (1990-91): «Europa, escenario de la inmigración del Este», en ITINERA. Anales de la Fundación Paulino Torras Domènech, pp. 75-94.

(1992): «La emigración de Europa Central y Oriental, tendencias e intereses en juego», en Política Exterior, n. ${ }^{\text {a }}$, pp. 41-56.

CONSEJO DE EUROPA (1991): Conferencia de ministros sobre los movimientos de personas provenientes de los países de Europa Central y Oriental. Vienea 24-25 de enero de 1991.

(1994): «La migration est-ouest en Europe», en Actividades del Consejo de Europa en el dominio de las migraciones, pp. 21-24.

FASSMANN, H., y MünZ, R. (1995): «La migration d'est en Europe (1918-1993)», en Revue Europeeenne des Migrations Internationales, vol. 11, n. $^{\circ} 3$, pp. 41-66.

GonzÁlez-YANCI, M. P., y AGuilera, M. J. (1996): «Los polacos en los nuevos flujos inmigratorios en España: una aceptación social diferente», en Espacio, Tiempo y Forma, serie VI, n. ${ }^{\circ}$ 9, Madrid, pp. 53-72.

GRECIC, V. (1993): «Mass migration from Eastern Europe: a challenge to the West?», en The new geography of European Migrations. Edited by Russell King. Belhaven Press. Londres.

GuIllon, M. (1989): «Refugiés et immigrés d'Europe de l'Est, en Revue Européenne des Migrations Internationals, vol. 5 , n. ${ }^{\circ}$, pp. 133-138.

GWIAZDA, A. (1992): «Emigración económica polaca y política de inmigración europea», en Boletín ICE Económico, n. 2340, pp. 3042-3044.

HersaK, E., y MESIC, M. (1990): «L'espace migratoire de Yougoslavie historique des migrations yougoslaves», en Revue Européenne des Migrations Internationals, vol. 6, n. ${ }^{\circ} 2,1990$.

HÖNEKOPP, E. (1993): «East-West migration: recent developments concerning Germany, and some future prospects», en The Changing course of international migration. OCDE, París, pp. 97-103.

KuPISZEwSKI, M. (1993): «Migration from Eastern Europe to European Community: Current trends and future developments», en Working Paper, 94/4. U. of Leeds. UK.

ÖBERG, S., y WILS, A. B. (1992): «East-West Migration in Europe. Can migration theories help estimate the numbers?», en Population Network Neusletter POPNET, n. ${ }^{\circ} 22,12 \mathrm{pp}$.

Okolski, M. (1991): «La nouvelle donne migratoire en Europe de L'Est», en REMI, vol. 7, n. ${ }^{\circ}$, pp. $7-40$.

RAmírez GoICoEcheA, E., «Europeos del Este», en Inmigrantes en España: vidas y experiencias», pp. 422-554. Madrid. Ed. CIS.

RHODE, B. (1993): «Brain drain, brain gain, brain waste: reflections on the emigration of highly educated and scientific personnel from Eastern Europe», en The New Geography of European Migration by Russell King. Belhaven Press. Londres, pp. 228245.

Rodríguez, V.; Aguilera, M. J. y GonzÁlez-Yanci, P. (1993): «Foreign minorities from Developing Countries in Madrid», en GeoJurnal, pp. 293-300.

SALT, J. (1993): «Evolution actuelle et future des migrations internationals en Europe», Conseil de l'Europe, $61 \mathrm{pp}$.

(1992): «The future of international labor migration», en International Migration Review, XXVI, 4, pp. 1077-1111. 
SOPEMI (1992): «Mouvements migratoires en Europe Centrale et Orientale: le cas de la Hungrie, de la Pologne et de la République Fédérative Tchèque et Slovaque», en Tendences des migrations internationales, París, OCDE, pp. 97-127.

(1997): Trends in international migration. Annual Report, 1996. OCDE, París, 272 pp. (véanse los informes de años anteriores).

VICHNEVSKI, A., y ZAYONTCHKOVSKAIA, J. (1991): «L'émigration de l'ex-Union soviétique: prémices et inconnues», en Revue Europeenne des Migrations Internationales, volumen 7, n. ${ }^{\circ} 3$, pp. 5-29.

WORACH-KARDAS, H. (1992): «Phases of life and migration (in Poland)», en Mass Migration in Europe. Implication in East and West, Viena.

RESUMEN: Los países del Este de nuevo foco de emigración de la Europa actual. Su incidencia en España. En el complejo espacio migratorio europeo, tanto los países del Este como España tienen un papel destacable. Con grandes analogías en el pasado, desde finales de los años ochenta han sufrido transformaciones, que llevan a los primeros a ser uno de los principales focos emisores de Europa, mientras que España se incorpora al grupo de los receptores. En este contexto se establece la relación entre ambos, siendo España hoy uno de los destinos de los emigrantes del Este, que constituyen un grupo con una posición intermedia en el abanico de flujos que llega al país, formado por los procedentes del primer mundo, cualificados, que ocupan puestos de trabajo importantes y se alinean con la población de mayor estatus socioeconómico y los del tercer mundo, poco cualificados y que se instalan junto a los estratos inferiores, presentando a menudo caracteres de marginalidad.

PALABRAS ClAVE: Migración, Europa Central y Oriental, Países del este, inmigración en España.

ABSTRACT: Eastern European countries once again a source of emigration in Europe today. Its affect on Spain. In the complex framework of European migration, both Eastern European countries and Spain play an important role. With great analogies in the past, transformations occurred at the end of the 1980s which have led Eastern European countries to be one of the main sources of emigrants in Europe. Spain is now on the receiving end. The relationship between the two is established in this context, with Spain today being one of the destinations of Eastern European emigrants, who are in an intermediate position within the array of peoples emigrating to the country - from highly-qualified first-world professionals holding important jobs and belonging to the highest socio-economic class to unskilled or under-skilled thirdworld emigrants living at the lower end of the socio-economic scale and often marginalized. Spain.

KEY wORDS: Migration, Eastern and Central Europe, Easterrn Europe, immigration in

RESUMÉ: Les pays de l'Est, nouveau foyer d'émitration de l'Europe actuelle. Incidence sur l'Espagne. Dans le complexe espace migratoire européen, aussi bien les pays de l'Est que l'Espagne ont un rôle considérable. Ayant de grandes analogies par le passé, depuis la fin des années 80 ils ont subi des transformations qui amènent les premiers à être l'un 
des principaux foyers d'émission de l'Europe, tandis que l'Espagne vient rejoindre le groupe des recepteurs. C'est dans ce contexte que s'établissent les rapports entre les deux, l'Espagne étant aujourd'hui l'une des destinations des émigrants de l'Est, qui constituent un groupe ayant une position intermédiaire sur l'éventail de flux arrivant au pays, formé par ceux provenant du premier monde, qualifiés, occupant des postes importants, et qui rejoignent la population ayant un plus haut statut socio-économique, et ceux du tiers monde, peu qualifiés et qui viennent rejoindre les niveaux inférieurs, présentant souvent des caractères de marginalité.

Mотs CLÉ: Migration, Europe Centrale et Orientale, Pays de l'Est, immigration en Espagne. 